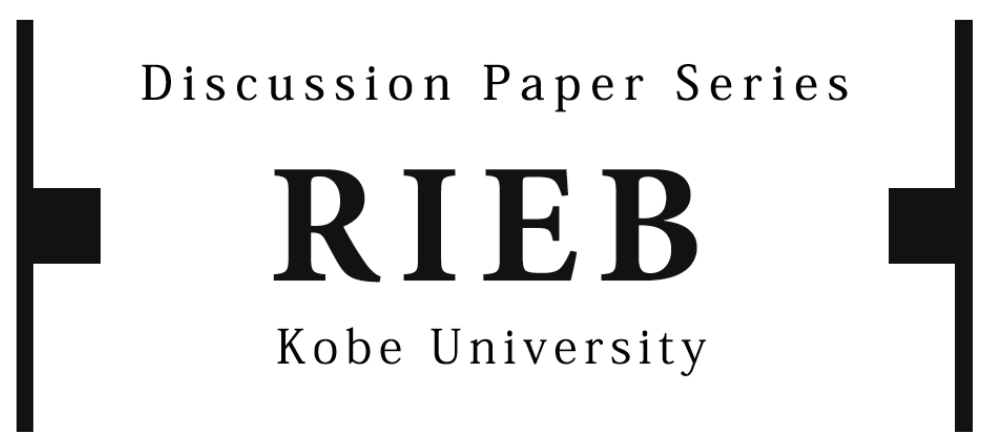

DP2014-10

Source of Underestimation of the Monetary Policy Effect: Re-examination of the Policy Effectiveness in Japan's 1990s

\title{
Masahiko SHIBAMOTO
}

Revised August 19, 2015

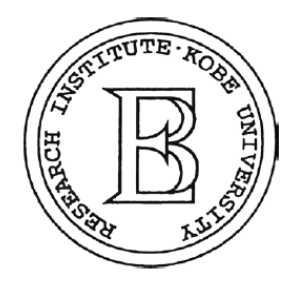

Research Institute for Economics and Business Administration Kobe University 


\title{
Source of underestimation of the monetary policy effect: Re-examination of the policy effectiveness in Japan's 1990s
}

\author{
Masahiko Shibamoto ${ }^{a, *}$ \\ ${ }^{a}$ Research Institute for Economics and Business Administration, Kobe University
}

July 22, 2015

\begin{abstract}
This paper re-examines empirical evidence on the potency of Japanese monetary policy in the 1990s by comparing the estimated impacts of various proxies for monetary policy shocks on the macroeconomy. My empirical results demonstrate that surprise target changes modeled as proxies for monetary policy shocks had impacts on real output and financial variables over the period 1990-2001. I also show that the estimated effects of identified monetary policy shocks depend on whether or not the shocks are expected: the monetary policy effects on the economy are underestimated when the empirical models fail to control for the market expectation for the monetary policy stance.
\end{abstract}

JEL Classification: E52; E58.

Keywords: monetary policy, surprise target changes, vector autoregression model, Japan.

\footnotetext{
${ }^{*}$ Research Institute for Economics and Business Administration, Kobe University, 2-1, Rokkodai, Nada, Kobe, 657-8501, Japan. E-mail: shibamoto@rieb.kobe-u.ac.jp.
} 


\section{Introduction}

The Japanese economy has been underperforming for decades. Since the burst of the bubble economy in 1992, the economy has suffered economic recessions, weak economic activity, asset price deflation, banking failures, and rising bankruptcies and unemployment. The Bank of Japan (BOJ) has maintained a prolonged easing policy stance in response to the sustained recession following the burst of the bubble economy.

Was the Japanese monetary policy effective in the 1990s? The literature remains divided on this question. Empirical studies such as Kuttner and Posen (2001) and Honda and Kuroki (2006) rely on a Keynesian view and argue that inadequate monetary stimulus led to inadequate aggregate demand. Other studies describe a structural change in the role of Japanese monetary policy during the 1990s and a loss of policy power due to a breakdown in the channel of transmission between interest rate adjustments and the real economy (e.g., Miyao (2000), Fujiwara (2006), Inoue and Okimoto (2008), and Nakajima, Kasuya, and Watanabe (2011)). A quantitative assessment of the potency of Japanese monetary policy in the 1990s could provide valuable insights, as the challenges of the 1990s appear to have many parallels to the outbreak of the global financial crisis in the last few years.

The method used to identify the exogenous component of monetary policy is key among the issues addressed in the literature analyzing the transmission and effects of the policy. A good number of papers develop vector autoregressive (VAR) models to estimate the effects of monetary policy shocks on macroeconomic variables (see Miyao (2000), Fujiwara (2006), Inoue and Okimoto (2008), and Nakajima, Kasuya, and Watanabe (2011)). Others, meanwhile, employ alternative methods to identify the exogenous monetary shocks. Honda and Kuroki (2006), for example, use information from a forward-looking market to divide the target changes in the call rate into expected and surprise components and then apply the methodology of Kuttner (2001) to interpret the surprise components as unexpected monetary policy shocks.

Kuttner (2001), Bernanke and Kuttner (2005), and Honda and Kuroki (2006) use an event study approach to identify how market interest rates and stock prices impact the expected and surprise changes. In an investigation of the one-day responses of changes in the policy 
target variable in Japan on stock prices and the term structure of interest rates for the period from July 1989 to March 2001, Honda and Kuroki (2006) find that changes in the surprise component of the target variable significantly affected stock prices and intermediate- and long-term interest rates. This supports the findings for the US reported by Kuttner (2001) and Bernanke and Kuttner (2005).

In this paper we seek to re-evaluate the dynamic effects of the Japanese monetary policy in the 1990s by comparing the estimated impacts of various proxies for monetary policy shocks on the real economy. In contrast to earlier studies applying the VAR models (e.g., Miyao (2000), Fujiwara (2006), Inoue and Okimoto (2008), Nakajima, Kasuya, and Watanabe (2011)), we use the surprise changes of the monetary policy target rate as the proxy variables for monetary policy shocks in Japan proposed by Honda and Kuroki (2006). ${ }^{1}$ Then, in a departure from the earlier studies using the event study approach (e.g., Kuttner (2001), Bernanke and Kuttner (2005), Honda and Kuroki (2006)), we investigate the intermediate- and long-term impacts of monetary policy shocks on real variables and financial variables. We also consider the importance of controlling market expectations regarding the monetary policy stance when using the VAR models to identify the monetary policy shocks.

Empirical findings from this paper attest to the effectiveness of the Japanese monetary policy of the 1990s, as policy shocks had significant impacts on macroeconomic variables. The findings also suggest that policy impacts are underestimated when the market expectations of the monetary policy stance are disregarded, as some policy changes are found to have been anticipated by market participants as endogenous responses to the stagnant real economy.

Our analysis gives us novel insight into the empirical assessment of the effectiveness of monetary policy, especially over the last few decades. This paper demonstrates, above all else, that the expected components of the monetary policy make it hard to identify the

\footnotetext{
${ }^{1}$ It may be useful to employ the factor augmented VAR (FAVAR) approach proposed by Bernanke, Boivin, and Eliasz (2005) as an alternative method for identifying the appropriate monetary policy shocks. FAVAR models have advantages and disadvantages. With the use of only a few factors to summarize numerous time series data, the models capture additional economic information not fully captured by the variables involved in the standard VAR models and reduce the risk of misspecifying the econometric model used to assess the effect of monetary policy shocks. A FAVAR model, however, is difficult to handle and requires complicated estimations. It is also inappropriate when working with only small samples (e.g., 60 months), as the degree of freedom is inadequate for model estimation. The econometric framework here in subsection 3.1, however, is very simple and readily available even with a relatively small sample.
} 
policy effects. In the process of reaching their policy decisions, the central banks have made notable efforts in recent years to inform the public of their views on the economy and the repercussions of monetary policy. ${ }^{2}$ The central banks have also actively used communication tools such as a forward guidance to manage expectations under the zero lower bound of the interest rate. ${ }^{3}$ Although these developments should help to enhance the effectiveness of monetary transmission, econometricians are now compelled to account for the private sector's expectations on the future course of monetary policy. ${ }^{4}$ It becomes ever more important to disentangle the anticipated and unanticipated components of monetary policy in an adequate manner when we assess the effectiveness of monetary policy.

The remainder of this paper is organized into three more sections. Section 2 briefly describes the essential concepts used to identify monetary policy shocks and reviews earlier accounts of how shocks are identified. Section 3 presents our empirical results by reporting the dynamic effects of monetary surprises on macroeconomic variables and then examining the differences among the various proxies for monetary policy shocks to explore the causes underlying underestimations of the monetary policy effect. Section 4 concludes this paper.

\section{$2 \quad$ Identifying monetary policy shocks}

When we quantitatively assess the efficacy of monetary policy, we examine whether the 'policyinduced' changes in the short-term nominal interest rate have an impact on real variables such as output and inflation. At the same time, the central bank systematically adjusts the shortterm interest rate in response to the movements and shocks in output and inflation. This is why we have to distinguish between the policy-induced changes and the systematic changes from observed policy rates. An essential step in investigating the efficacy of a monetary policy is to isolate the policy-induced changes, the so-called monetary policy shocks, in actual

\footnotetext{
${ }^{2}$ Bernanke (2004), Blinder, Ehrmann, Fratzscher, De Haan, and Jansen (2008), among others, among others, stress the importance of communicating with the market when the central banks implement monetary policy.

${ }^{3}$ Even when facing the zero lower bound on short-term policy interest rates, the central bank can stimulate the economy by managing expectations (see Eggertsson and Woodford (2003), Bernanke and Reinhart (2004), and Bernanke, Reinhart, and Sack (2004)).

${ }^{4}$ Two dimensions related to the policy rate change, namely, (i) the change in the 'current' policy rate and (ii) change in the 'future' policy rate path (forward guidance), are identified in several studies (see Kohn and Sack (2004), Bernanke, Reinhart, and Sack (2004), Gürkaynak, Sack, and Swanson (2005) and Brand, Buncic, and Turunen (2010)).
} 
economies.

We begin by considering the monetary policy reaction function when analyzing the transmission mechanism of monetary policy shocks in macroeconomics. The monetary policy reaction function shows how central banks adjust short-term interest rates in response to various elements in the macroeconomy. Taylor (1995), for instance, argues that any analysis of the monetary policy transmission mechanism should involve examination of the central bank's reaction function. The reaction function is expressed by including a monetary policy variable $r_{t}$ and the monetary authority's information set $\Omega_{t}$ :

$$
r_{t}=f\left(\Omega_{t}\right)+\eta_{t} .
$$

where $f\left(\Omega_{t}\right)$ is the part decided based on $\Omega_{t}$, the information set used by the monetary authority for policy decisions on the fluctuation of monetary policy variables. Hence, the first term on the right-hand side of (1) is the fluctuating part of a monetary policy variable that is endogenously determined, in other words, the 'policy reaction' or 'policy rule.' The second term $\eta_{t}$ on the right-hand side of (1) is the exogenous change in the monetary policy variable not based on the information set $\Omega_{t}$; in other words, $\eta_{t}$ is the change in the monetary policy variable that does not rely on the current or past state of the economy. This is the "monetary policy shock.'

The approaches for identifying monetary policy shocks in the empirical literature on monetary policy can be roughly classified into two types, depending on how monetary policy is measured. The first is the 'VAR-based approach.' The second is the 'signal-extraction approach,' an approach that drives the shocks from changes in futures prices around policy changes.

\subsection{VAR-based approach}

The VAR-based approach uses a structural VAR model to identify monetary policy shocks. A considerable body of literature recently published attempts to use VAR models to identify and measure the effects of monetary policy shocks on macroeconomic variables.

An ordinary VAR model describes the dynamic movements of endogenous variables by 
their own past values. Yet a VAR model is reduced in form and its equations lack economic interpretation. For our purpose of analyzing monetary policy effect, we have no way of determining what the 'monetary policy' is in a VAR. We therefore need to identify the underlying structure of the economy reflected in the VAR, in particular that of monetary policy reaction and its innovation, in order to measure the true monetary policy effect. Some authors interpret unanticipated call rate shocks as the monetary policy shocks and identify the monetary policy shocks in Japan (e.g., Miyao (2000, 2002), Ogawa (2000, 2002), Ford, Agung, Ahmed, and Santoso (2003), Shibamoto (2007), Inoue and Okimoto (2008), Nakajima, Kasuya, and Watanabe (2011)). ${ }^{5}$ The VAR approach is useful for such a purpose as it allows us to analyze the dynamic effects of economic variables without requiring a particular theoretical model. ${ }^{6}$

West (1993), Shioji (2000), Miyao (2002), Braun and Shioji (2006) and Shibamoto (2007) use VAR models to empirically demonstrate that the Japanese monetary policy significantly affects financial markets and the real economy. In an estimation of a VAR model consisting of a call rate, monetary base, stock price, and IIP, all in first differences, Miyao (2002) finds that monetary policy shocks have a persistent effect on real output in the late 1980s. ${ }^{7}$

In a report from Miyao (2000) showing a possible structural break in the role of Japan's

\footnotetext{
${ }^{5}$ Kasa and Popper (1997) and Nakashima (2006) study monetary policy in Japan by means of the Bernanke and Mihov (1998), where the measure of stance in monetary policy is derived from an estimated model of the central bank's operating procedure in the structural VAR. Kasa and Popper (1997) argue that the Bank of Japan targets a weighted average for the call rate and nonborrowed reserves.

${ }^{6}$ For a more detailed account of the identification issues involved in estimating the economic effects of a monetary policy shock using the VAR approach, see Christiano, Eichenbaum, and Evans (1999).

${ }^{7}$ West (1993), Shioji (2000), Miyao (2002), Braun and Shioji (2006), and Shibamoto (2007) all study the role of Japan's monetary policy with their own selected policy variables and identification frameworks. West (1993) adopts a nonrecursive identification framework to Japan's innovations in the money supply (M2) equation as monetary policy shocks. In a study applying a nonrecursive identification framework with monetary policy variables (the Bank of Japan loan and high-powered money), Shioji (2000) concludes that a model better describes Japanese monetary policy if it assumes that the central bank controls the total amount of highpowered money rather than only a specific component of high-powered money. Miyao (2002) argues that the institutional features of the Bank of Japan's operating procedures under the conventional policy setting fit a simple recursive identification approach similar to those of Sims (1992) and Christiano, Eichenbaum, and Evans (1999), where disturbances in the short-term interest rate equation are viewed as the exogenous part of monetary policy and the interest rate is placed before monetary aggregates in the ordering. Braun and Shioji (2006) use use two alternative sign restrictions where a surprise tightening in monetary policy either increases the short-term nominal interest rate and lowers output, prices, monetary aggregates on the one hand, or lowers the short-term nominal interest rate and lowers output, prices, monetary aggregates on the other hand. Braun and Shioji (2006) argue that monetary policy has large and persistent effects on the economy under the latter assumption. Shibamoto (2007) uses the FAVAR model to identify the monetary policy shocks. Although these papers identify monetary policy shocks under different restriction assumptions, their empirical results are quite similar; the maximum estimated output effect in response to a one-standard-deviation monetary policy shock is about 0.45 percent.
} 
monetary policy during the 1990s, the persistent effect of monetary policy on real output disappears with a subsample of that decade. In later studies using VAR models similar to that from Miyao (2000) but allowing for the time-varying coefficients and error variances, Inoue and Okimoto (2008) and Nakajima, Kasuya, and Watanabe (2011) conclude that the interest rate cut is ineffective in stimulating the macroeconomy from 1996 onward.

\subsection{Signal-extraction approach}

The signal-extraction approach estimates monetary policy shocks directly from daily data on policy-induced short-term interest rates. Rudebusch (1998), Kuttner (2001), Bernanke and Kuttner (2005), Cochrane and Piazzesi (2002), Faust, Swanson, and Wright (2004), and Honda and Kuroki (2006) all follow this approach.

Honda and Kuroki (2006) divide the call-rate target changes into expected and surprise components using information from a forward-looking market and interpret the surprise components of the call-rate target changes as the unexpected monetary policy shocks, repeating the same basic steps described by Kuttner (2001). Specifically, they apply the event-study approach to the Japanese economy by carefully reviewing articles in the Nikkei News Paper to identify the dates of the call-rate target changes and target levels (or ranges). Next, they decompose the call-rate target changes into the expected and surprised components based on the information from the nearest-term three-month Euro-Yen futures market. With this information, they investigate how changes in the policy target variable affect stock prices and the term structure of interest rates for the period from July 1989 to March 2001. They find that a surprise decrease in the call rate target significantly affects aggregate stock returns and intermediate-term and long-term interest rates.

\section{Econometric Analysis}

\subsection{Dynamic effects of surprise changes in monetary policy}

This subsection estimates the dynamic effects of the monetary policy shocks on the macroeconomy. Specifically, we use surprise changes in the monetary policy target rate as the proxy 
variables for monetary policy shocks in Japan proposed by Honda and Kuroki (2006). The interest rate and stock price responses to the changes in Honda and Kuroki (2006) cover only one day, a period considerably shorter than the commonly recognized time lags before monetary policy effects are sometimes transmitted throughout an economy. For this reason, we focus here on the intermediate and long-term impacts of surprise monetary changes on real variables such as output and inflation, and financial variables such as stock prices.

To investigate the dynamic effects of surprise changes in monetary policy, we calculate the impulse responses of macroeconomic variables $x_{n}$. Borrowing from Cochrane and Piazzesi (2002), we run the following single regressions of the changes in macroeconomic variables $x_{n, t}$ on the policy shocks $\epsilon_{M P, t}$ up to $h$ horizons;

$$
\Delta x_{n, t+j}=\alpha_{n, j}+\beta_{n, j} \epsilon_{M P, t}+e_{n, t+j}
$$

for $j=0, \cdots, h$. Based on the regressions above, we can calculate the impulse response at the level for horizon $i$ as $\sum_{j=0}^{i} \hat{\beta}_{n, j}$.

We consider the surprise changes in monetary policy as proxy variables for the monetary policy shocks $\epsilon_{M P, t}$. To construct monthly surprise changes in monetary policy, we sum up the daily series provided by Honda and Kuroki (2006) Table $1 .^{8}$

For $x_{n, t}$, we select the following four key macroeconomic variables: the uncollateralized overnight call rate (CALL), consumer price index excluding perishables (Core CPI), Tokyo stock price index (TOPIX), index of industrial production (IIP). ${ }^{9}$ All of the variables except the interest rates are expressed in logarithms and multiplied by 100 .

The sample period is from September 1990 to March 2001. Following Miyao (2000), the sample period starts from the month following the policy move by the BOJ to raise the official discount rate to $6 \%$. The sample period ends in the month following the month when the operating target is changed from the uncollateralized overnight call rate to the amount outstanding for the current accounts of financial institutions (that is, reserves) at the BOJ.

\footnotetext{
${ }^{8}$ On several occasions, the BOJ spent several days adjusting the overnight rate to a new target rate. In some cases, the target change took place from the end of the month to the beginning of the next month. Here we treat each case as a surprise change in the monetary policy in the next month: in the case of the surprise change of $-0.15 \%$ over the period March 31-April 3, the change is treated as that in April.

${ }^{9}$ See the Appendix for details on the data series.
} 
Figure 1 shows the estimated impulse responses. To simplify the comparison below, a monetary policy shock is normalized to produce a 25-basis-point rise in the call rate on impact. The solid line indicates the estimated response for each of the variables in levels up to 30 months. The dotted lines represent standard error bands.

Overall, this figure shows that the Japanese monetary policy in the 1990s had plausible effects in comparison to what the discussions of monetary policy effects in the macroeconomic textbooks would predict, but effects that run counter to the arguments of Miyao (2000), Fujiwara (2006), Inoue and Okimoto (2008), and Nakajima, Kasuya, and Watanabe (2011). The responses of the IIP to the positive surprise changes in the monetary target rate were persistently negative. This implies that the unexpected expansion in Japanese monetary policy in the 1990s surely increased the level of real activity. The results in Figure 1 also clearly demonstrate that the time lags with which the monetary policy shock is transmitted vary among the various economic variables. The IIP declines to its lowest values roughly two years after a monetary tightening, then gradually works its way back up to zero. The CPI stays flat for roughly 18 months, then declines steadily for two years to its nadir, with longlasting effects. These responses in domestic prices indicate a price rigidity. Similar results have been reported in the US by Christiano, Eichenbaum, and Evans (1999) and Bernanke, Boivin, and Eliasz (2005), and in Japan in a recent paper of my own (Shibamoto, 2007). ${ }^{10}$

\subsection{Source of underestimation of monetary policy effect}

In contrast with our results in the previous subsection, a good number of studies that apply the VAR models suggest that Japanese monetary policy was not effective in the 1990s. When Miyao (2000), Inoue and Okimoto (2008), and Nakajima, Kasuya, and Watanabe (2011) use VAR models to identify and measure the effects of exogenous monetary policy shocks on macroeconomic variables, they find a structural break in the role of Japanese monetary policy during the 1990s. Specifically, they suggest that the Japanese monetary policy shocks of the 1990s had smaller impacts on macroeconomic variables such as IIP than the shocks of the

\footnotetext{
${ }^{10}$ In an analysis of monetary policy shocks in Japan with a FAVAR approach, Shibamoto (2007) finds that monetary policy shocks had a strong impact on employment, housing starts, and several other real variables over the period 1989-2001.
} 
1970s and 1980s. In this subsection we confirm their findings, but also seek to reconcile our results in the previous subsection with the results obtained using VAR models.

First, to identify the VAR shocks, we consider the simple 4-variable VAR model. Following the method of Miyao (2000), Inoue and Okimoto (2008), and Nakajima, Kasuya, and Watanabe (2011), the reduced-form VAR consists of the IIP, real effective exchange rate (RER), CALL, and monetary base (MB). ${ }^{11}$ The series for the variables IIP, RER, and MB are transformed using the first difference. Shocks are orthogonalized recursively in that order, and the VAR is estimated with 10 monthly lags. ${ }^{12}$

Figure 2 show the estimated impulse responses using $\epsilon_{M P, t}$ identified by 4 -variable VARs. We confirm that the monetary policy shocks identified by the 4-variable VARs have limited impacts on real output, that is, impacts no greater than the shocks in the 1990s reported by Miyao (2000), Fujiwara (2006), Inoue and Okimoto (2008), and Nakajima, Kasuya, and Watanabe (2011).

While the VARs are certainly very useful for identifying monetary policy shocks, some of what the VAR identification scheme classifies as shocks to monetary policy may be well anticipated. Indeed, the shocks identified by the VARs reflect factors omitted from the VARs. If these factors are correlated with the systematic movements of the interest rate, then the VAR estimates will contain omitted variable bias.

The central banks systematically change their policy stances in response to certain symptoms of economic downturn and deflationary pressure, even when current real output and inflation hold steady. If we account for the effects of demand contraction on real output, we would expect the outputs to fall after monetary expansion (though by less than they would have fallen without the expansion). Suppose, however, that VARs omit variables that reflect such forward-looking movements by the central banks. When these omitted variables intimate a downward pressure on the economy, the central banks cut their interest rates. These VAR

\footnotetext{
${ }^{11}$ See the Appendix for the data source in RER and MB.

${ }^{12}$ In the present ordering we treat the IIP as the most exogenous variable, following the example of Christiano, Eichenbaum, and Evans (1999), among others. Given the institutional characteristics of the BOJ 's operation procedures, we again follow Miyao (2002) by assuming that the call rate is predetermined for the monetary base. Then we estimate the VAR models imposing the 4-variable system in two different orderings that maintain the above assumptions, i.e., (IIP, CALL, RER, MB) and (IIP, CALL, MB, RER). Our benchmark results turn out to be quite robust for these two orderings.
} 
interest rate shocks then presage decreases in output. That is, the VAR mistakenly regards these decreases in interest rates as monetary policy shocks, because of the omitted variables. This leads to biased estimates of the impulse responses. As such, we should identify the monetary policy shocks that cannot be predicted based on the information set by the market participants available up to the period $t$. In other words, if any variable contains information content about future monetary policy shocks, any attempt to use the shocks to analyze the effects of the monetary policy and monetary transmission would invite serious problems. ${ }^{13}$

Here we formally test the possibility as above. Specifically, we conduct the Granger causality test to examine whether lagged values of one variable help to predict the shocks identified by the 4 variable VARs.

As Table 1 shows, the lagged values of the first difference of the Euro-Yen Futures rate, 3month TIBOR rate, and monthly expected changes constructed by summing up the daily series from Honda and Kuroki (2006), series that reflect the market expectation of the monetary policy stance in the near future, Granger-cause the shocks identified by the 4-variable VARs. This means that market participants can forecast much of what 4-variables VARs are labeling as monetary policy shocks. This therefore implies that the shocks identified by the 4 -variable VARs should be inappropriate, because the identified shocks in no way reflect the exogenous behavior of the monetary authority. The limited responses of real output, etc. to interest rate innovations in Figure 2 fit this interpretation when the innovations include the expected changes of monetary policy.

Table 1 also shows that surprise changes Granger-cause the VAR shocks, while the VAR shocks cannot be found to Granger-cause the surprise changes. This implies that surprise changes in the call rate are predetermined and can be characterized as 'policy-induced' changes in the short-term nominal interest rate.

A natural way to control the market expectation of the monetary policy stance is to incorporate the variables that reflect the market expectation of the monetary policy stance in the near future into a VAR model. Thus, we include the Euroyen futures rate into the

\footnotetext{
${ }^{13}$ This interpretation is logically similar to that for the 'price puzzle' of Sims (1992). In his explanation of the 'price puzzle,' the persistent rise responses of prices to monetary tightening can be interpreted as the consequences of imperfect control for any information the central bank may have on future inflation.
} 
4-variable VARs in the context described by Rudebusch (1998), Kuttner (2001), Bernanke and Kuttner (2005), Cochrane and Piazzesi (2002), Faust, Swanson, and Wright (2004), and Honda and Kuroki (2006).

Figure 3 shows the impulse responses estimated using $\epsilon_{M P, t}$ identified by 5 -variable VARs for the IIP, RER, CALL, MB, and Euroyen 3-month future rate. A comparison between this figure and Figure 2 reveals noticeable differences. Specifically, the responses of the IIP to positive monetary policy shocks are persistently negative. We also find, meanwhile, that the effects of the surprise monetary policy changes in this figure are generally similar to those in Figure 1. This implies that the Euroyen 3-month future rate plays an important role in controlling the market expectations of monetary policy stance. Even when using the VAR model to identify the monetary policy shocks, we find that the shocks in the 1990s have statistically significant impacts on the real economy and financial markets.

\section{Concluding Remarks}

This paper re-examines the effects of the Japanese monetary policy in the 1990s. We find that the policy brought about the intended effects through the channels of transmission between interest rate adjustments and the real economy. Our evidence also suggests that we underestimate the effects of the monetary policy shocks on the real economy when the empirical models fail to control for the market expectation for monetary policy stance.

The accommodative, endogenous policy response to future economic conditions may have made it more difficult to identify the effects of the exogenous monetary policy. The BOJ steadily loosened its monetary policy during Japan's Lost Decade, maintaining a mostly accommodative stance with an emphasis on communication with market participants in the stagnant real economy. The BOJ's policy was clearly intended to prevent future economic downturns and deflationary pressures, but the policy made it increasingly difficult for econometricians to avert failure in their efforts to control for systematic policy responses. Although Miyao (2000), Fujiwara (2006), Inoue and Okimoto (2008), and Nakajima, Kasuya, and Watanabe (2011) point out a possible structural change in the role of Japanese monetary policy during the 1990s, empirical evidence in this paper implies that this structural change 
should not reflect a loss of monetary policy power, but rather a difficulty in identifying the exogenous monetary policy changes. This implication is consistent with the arguments on the financial market from Kuttner (2001). ${ }^{14}$

This paper focuses on the monetary policy effects under the traditional short-term interest rate control up to March 2001. From March 2001 to March 2006, the BOJ used the quantity of bank reserves as an instrument under what is described as a 'quantitative easing monetary policy' (QEMP). The major central banks that have adopted de facto QEMP in response to the recent financial crisis (e.g., the Federal Reserve, the European Central Bank, and the Bank of England) can benefit from an understanding of the effectiveness and transmission mechanism of the Japanese QMEP. Though empirical research on the effectiveness of QEMP has been published, we reach no consensus on this issue here. The effects of QEMP on real output and inflation are particularly controversial. ${ }^{15}$ The identification of monetary policy shocks can of course be key in investigating the efficacy of the Japanese QEMP. ${ }^{16}$ This is beyond the scope of this paper but worthy of future research.

\section{Appendix. Data}

The following summarizes the data used and their sources. All the variables except for the 3-month Euroyen Futures are taken from the Nikkei NEEDS database.

- IIP: Index of Industrial Production (Mining and Manufacturing, 2000 average=100)

\footnotetext{
${ }^{14}$ Kuttner (2001) suggests that the effects in the 1980s and 1990s were evidently weaker not because policy shocks had smaller impacts, but because these policy shocks were anticipated soon before they took place.

${ }^{15}$ See Honda, Kuroki, and Tachibana (2007), Inoue and Okimoto (2008), and Shibamoto and Tachibana (2013) for pro, and Kimura, Kobayashi, Muranaga, and Ugai (2003), Fujiwara (2006), and Nakajima, Kasuya, and Watanabe (2011) for con.

${ }^{16}$ In the US and the UK, Baumeister and Benati (2012) and Kapetanios, Mumtaz, Stevens, and Theodoridis (2012) estimate a time-varying parameter structural VAR and identify narrowing long-short spreads of government bonds with the sign restrictions. Specifically, they find no declines in output or prices in response to accommodative monetary policy shocks as unconventional monetary policy shocks. Gambacorta, Hofmann, and Peersman (2014) estimate a panel VAR from eight advanced countries, including Japan, over a sample spanning the period from the onset of the recent global financial crisis onward. They identify unconventional monetary policy shocks by imposing a mixture of zero and sign restrictions such that an exogenous increase in central bank balance sheets at the zero lower bound has no contemporaneous impact on output or prices, and immediately mitigates financial market uncertainty measured by VIX. In Japan, for example, Shibamoto and Tachibana (2013) estimate a structural VAR model with simultaneous interaction between stock prices and policy decisions and identify the policy-induced changes in current account balances as unconventional monetary policy shocks during the Japanese QEMP period. See Shibamoto and Tachibana (2013) for details on the differences among empirical studies on the effect of Japanese monetary policy under a low interest rate.
} 
- RER: Real Effective Exchange Rate (March 1973=100)

- CALL: Uncollateralized Overnight Call Rate (Month Average)

- MB: Monetary Base, adj. for Reserve Requirement Changes, Average Outstanding (100 million Yen)

- 3MTIBOR: Tokyo Interbank Offered Rate, Euroyen deposit, 3 Months (Japanese Bankers Association)

- Core CPI: Consumer price index, excluding fresh foods (2010 average $=100$ )

- TOPIX: Tokyo Stock Price Index

- 3-month Euroyen Futures: 100 - Three-Month Euroyen TIBOR Futures settlement price (Monthly Average) (from the Datastream database)

All of the variables are transformed into logarithms and multiplied by 100, except for the interest rate series.

\section{Acknowledgements}

I extend my special thanks to Ryuzo Miyao for his extensive help and encouragement in the writing of this paper. I am also grateful to Takeo Hoshi, Takashi Kamihigashi and the seminar participants at the University of California, San Diego, for their helpful comments and suggestions. This study was funded by a Grant-in-Aid from the Japanese Ministry of Education. 


\section{References}

Baumeister, C., and L. Benati (2012): "Unconventional Monetary Policy and the Great Recession: Estimating the Macroeconomic Effects of a Spread Compression at the Zero Lower Bound," Bank of Canada Working Papers, (12-21).

Bernanke, B. S. (2004): "Fedspeak," A Speech at the Meetings of the American Economic Association, San Diego, California.

Bernanke, B. S., J. Boivin, And P. S. Eliasz (2005): "Measuring the Effects of Monetary Policy: A Factor-augmented Vector Autoregressive (FAVAR) Approach," Quarterly Journal of Economics, 120(1), 387-422.

Bernanke, B. S., And K. N. Kuttner (2005): "What Explains the Stock Market's Reaction to Federal Reserve Policy?," Journal of Finance, 60(3), 1221-1257.

Bernanke, B. S., And I. Minov (1998): "Measuring Monetary Policy," Quarterly Journal of Economics, 113(3), 869-902.

Bernanke, B. S., and V. R. Reinhart (2004): "Conducting Monetary Policy at Very Low Short-Term Interest Rates," American Economic Review, 94(2), 85-90.

Bernanke, B. S., V. R. Reinhart, and B. P. SaCk (2004): "Monetary Policy Alternatives at the Zero Bound: An Empirical Assessment," Brookings Papers on Economic Activity, $35(2), 1-100$.

Blinder, A. S., M. Ehrmann, M. Fratzscher, J. De Haan, and D.-J. Jansen (2008): "Central Bank Communication and Monetary Policy: A Survey of Theory and Evidence," Journal of Economic Literature, 46(4), 910-45.

Brand, C., D. Buncic, and J. Turunen (2010): "The Impact of ECB Monetary Policy Decisions and Communication on the Yield Curve," Journal of the European Economic Association, 8(6), 1266-1298.

Braun, R. A., and E. Shioji (2006): "Monetary Policy and the Term Structure of Interest Rates in Japan," Journal of Money, Credit and Banking, 38(1), 141-162. 
Christiano, L. J., M. Eichenbaum, and C. L. Evans (1999): "Monetary Policy Shocks: What Have We Learned and to What End?," in Handbook of Macroeconomics, ed. by J. B. Taylor, and M. Woodford, vol. 1, pp. 65-148. North-Holland, Amsterdam.

Cochrane, J. H., And M. Piazzesi (2002): "The Fed and Interest Rates - A High-Frequency Identification," American Economic Review, 92(2), 90-95.

Eggertsson, G. B., And M. Woodford (2003): "The Zero Interest-Rate Bound and Optimal Monetary Policy," Brookings Papers on Economic Activity, (1), 139-211.

Faust, J., E. T. Swanson, and J. H. Wright (2004): "Identifying VARs Based on High Frequency Futures Data," Journal of Monetary Economics, 51(6), 1107-1131.

Ford, J. L., J. Agung, S. Ahmed, and B. Santoso (2003): "Bank Behaviour and the Channel of Monetary Policy in Japan, 1965-1999," Japanese Economic Review, 54(3), 275299.

Fujiwara, I. (2006): "Evaluating Monetary Policy When Nominal Interest Rates Are Almost Zero," Journal of the Japanese and International Economies, 20(3), 434-453.

Gambacorta, L., B. Hofmann, and G. Peersman (2014): "The Effectiveness of Unconventional Monetary Policy at the Zero Lower Bound: A Cross-Country Analysis," Journal of Money, Credit, and Banking, 46(4), 615-642.

Gürkaynak, R. S., B. Sack, and E. Swanson (2005): "Do Actions Speak Louder Than Words? The Response of Asset Prices to Monetary Policy Actions and Statements," International Journal of Central Banking, 1(1).

Honda, Y., And Y. Kuroki (2006): "Financial and Capital Markets' Response to Changes in the Central Bank's Target Interest Rate: The Case of Japan," Economic Journal, 116(513), $812-842$.

Honda, Y., Y. Kuroki, and M. Tachibana (2007): "An Injection of Base Money at Zero Interest Rates: Empirical Evidence from the Japanese Experience 2001-2006," Discussion 
Papers in Economics and Business 07-08, Osaka University, Graduate School of Economics and Osaka School of International Public Policy (OSIPP).

Inoue, T., And T. Okimoto (2008): "Were There Structural Breaks in the Effects of Japanese Monetary Policy? Re-Evaluating Policy Effects of the Lost Decade," Journal of the Japanese and International Economies, 22(3), 320-342.

Kapetanios, G., H. Mumtaz, I. Stevens, and K. Theodoridis (2012): "Assessing the Economy-Wide Effects of Quantitative Easing," Economic Journal, 122(564), F316-F347.

Kasa, K., And H. Popper (1997): "Monetary Policy in Japan: A Structural VAR Analysis," Journal of the Japanese and International Economies, 11(3), 275-295.

Kimura, T., H. Kobayashi, J. Muranaga, and H. Ugai (2003): "The Effect of the Increase in the Monetary Base of Japan's Economy at Zero Interest Rates: An Empirical Analysis," in Monetary Policy in a Changing Environment, pp. 276-312. Bank for International Settlements, Basle.

Kohn, D., And B. SACK (2004): "Central Bank Talk: Does It Matter and Why?," in Macroeconomics, Monetary Policy, and Financial Stability, pp. 175-206. Ottawa: Bank of Canada.

Kuttner, K. N. (2001): "Monetary Policy Surprises and Interest Rates: Evidence from the Fed Funds Futures Market," Journal of Monetary Economics, 47(3), 523-544.

Kuttner, K. N., And A. S. Posen (2001): "The Great Recession: Lessons for Macroeconomic Policy from Japan," Brookings Papers on Economic Activity, (2), 93-185.

Miyao, R. (2000): "The Role of Monetary Policy in Japan: A Break in the 1990s?" Journal of the Japanese and International Economies, 14(4), 366-384.

(2002): "The Effects of Monetary Policy in Japan," Journal of Money, Credit, and Banking, 34(2), 376-392. 
Nakajima, J., M. Kasuya, and T. Watanabe (2011): "Bayesian Analysis of Time-Varying Parameter Vector Autoregressive Model for the Japanese Economy and Monetary Policy," Journal of the Japanese and International Economies, 25(3), 225-245.

Nakashima, K. (2006): "The Bank of Japan's Operating Procedures and the Identification of Monetary Policy Shocks: A Reexamination Using the Bernanke-Mihov Approach," Journal of the Japanese and International Economies, 20(3), 406-433.

Ogawa, K. (2000): "Monetary Policy, Credit, and Real Activity: Evidence from the Balance Sheet of Japanese Firms," Journal of the Japanese and International Economies, 14(4), $385-407$.

(2002): "Monetary Transmission and Inventory: Evidence from Japanese BalanceSheet Data by Firm Size," Japanese Economic Review, 53(4), 425-443.

Rudebusch, G. D. (1998): "Do Measures of Monetary Policy in a VAR Make Sense?," International Economic Review, 39(4), 907-931.

Shibamoto, M. (2007): "An Analysis of Monetary Policy Shocks in Japan: a Factor Augmented Vector Autoregressive Approach," Japanese Economic Review, 58(4), 484-503.

Shibamoto, M., And M. Tachibana (2013): "The Effect of Unconventional Monetary Policy on the Macro Economy: Evidence from Japan's Quantitative Easing Policy Period," Research Institute for Economics \& Business Administration Discussion Paper Series DP2013-12, Kobe University.

ShioJi, E. (2000): "Identifying Monetary Policy Shocks in Japan," Journal of the Japanese and International Economies, 14(1), 22-42.

Sims, C. A. (1992): "Interpreting the Macroeconomic Time Series Facts : The Effects of Monetary Policy," European Economic Review, 36(5), 975-1000.

TAYLOR, J. B. (1995): “The Monetary Transmission Mechanism: An Empirical Framework," Journal of Economic Perspectives, 9(4), 11-26. 
West, K. D. (1993): “An Aggregate Demand-Aggregate Supply Analysis of Japanese Monetary Policy, 1973-1990,” in Japanese Monetary Policy, ed. by K. J. Singleton, pp. 161-189. 
Table 1: Granger causality tests

\begin{tabular}{lc}
\hline Hypothesis test & p-value in parenthesis \\
\hline Do $\Delta$ EDFs Granger-cause VAR shocks? & Yes $(0.032)$ \\
Do $\Delta$ 3MTIBORs Granger-cause VAR shocks? & Yes $(0.005)$ \\
Do expected changes Granger-cause VAR shocks? & Yes $(0.047)$ \\
Do surprise changes Granger-cause VAR shocks? & Yes $(0.016)$ \\
Do VAR shocks Granger-cause surpreise changes? & No $(0.834)$ \\
\hline
\end{tabular}

Notes: VAR shocks were estimated by regressing the reduced-form VAR consisting of the first difference of IIP, RER, CALL, and MB with 10 monthly lags and orthogonalizing recursively in that order. Monthly expected and surprise monetary policy changes are constructed by summing up the daily series provided by Honda and Kuroki (2006) Table 1. One lag is used in the Granger-causality tests. 

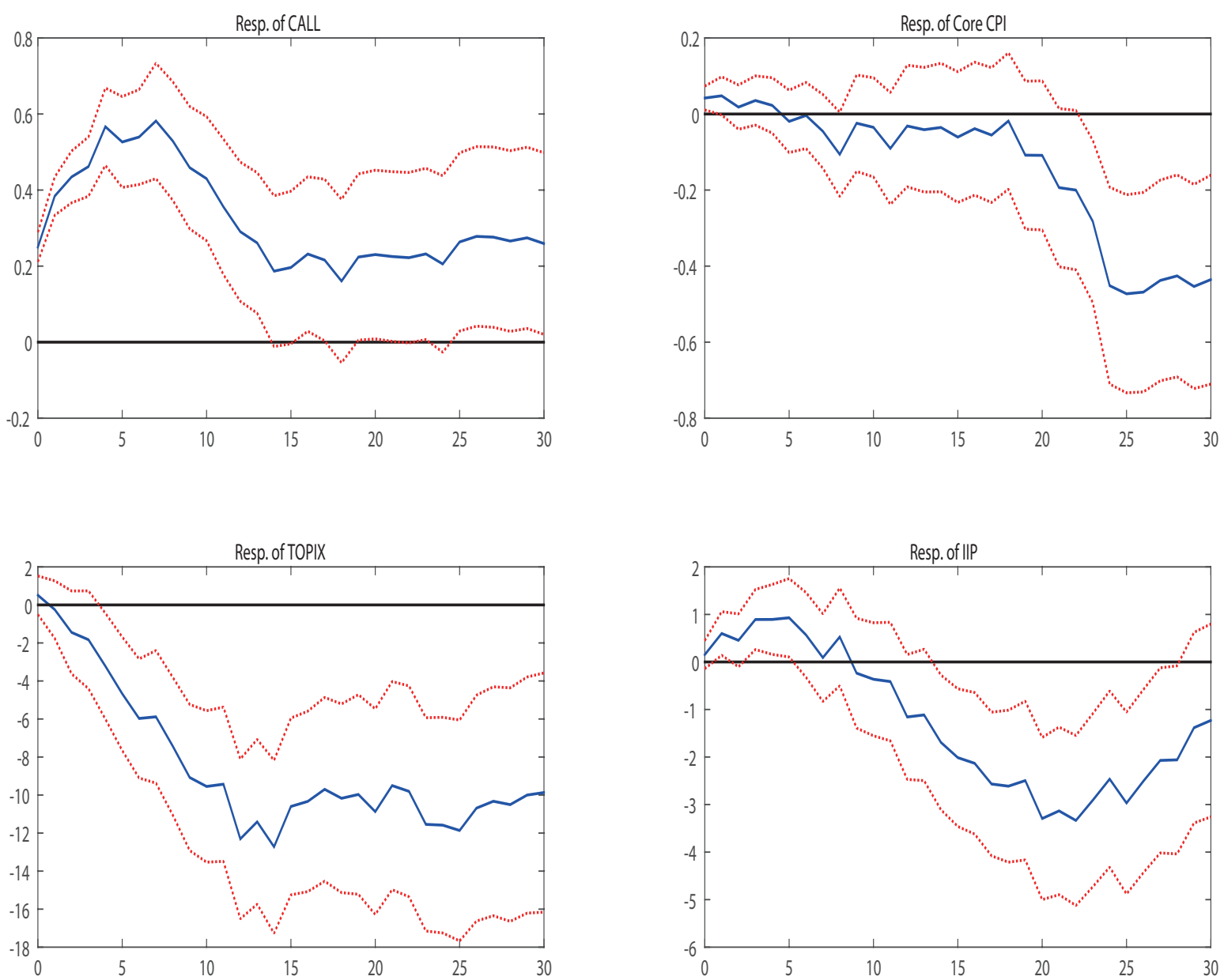

Figure 1: Impulse Responses to a Monetary Policy Surprise Change

Note: The solid lines represent the point estimates of the impulse responses to a surprise change in monetary policy. The shock size is normalized to produce a 25 -basis-point rise in the call rate on impact. The dotted lines represent standard error bands. The horizontal axis denotes the months from the shock (up to 30 months). 

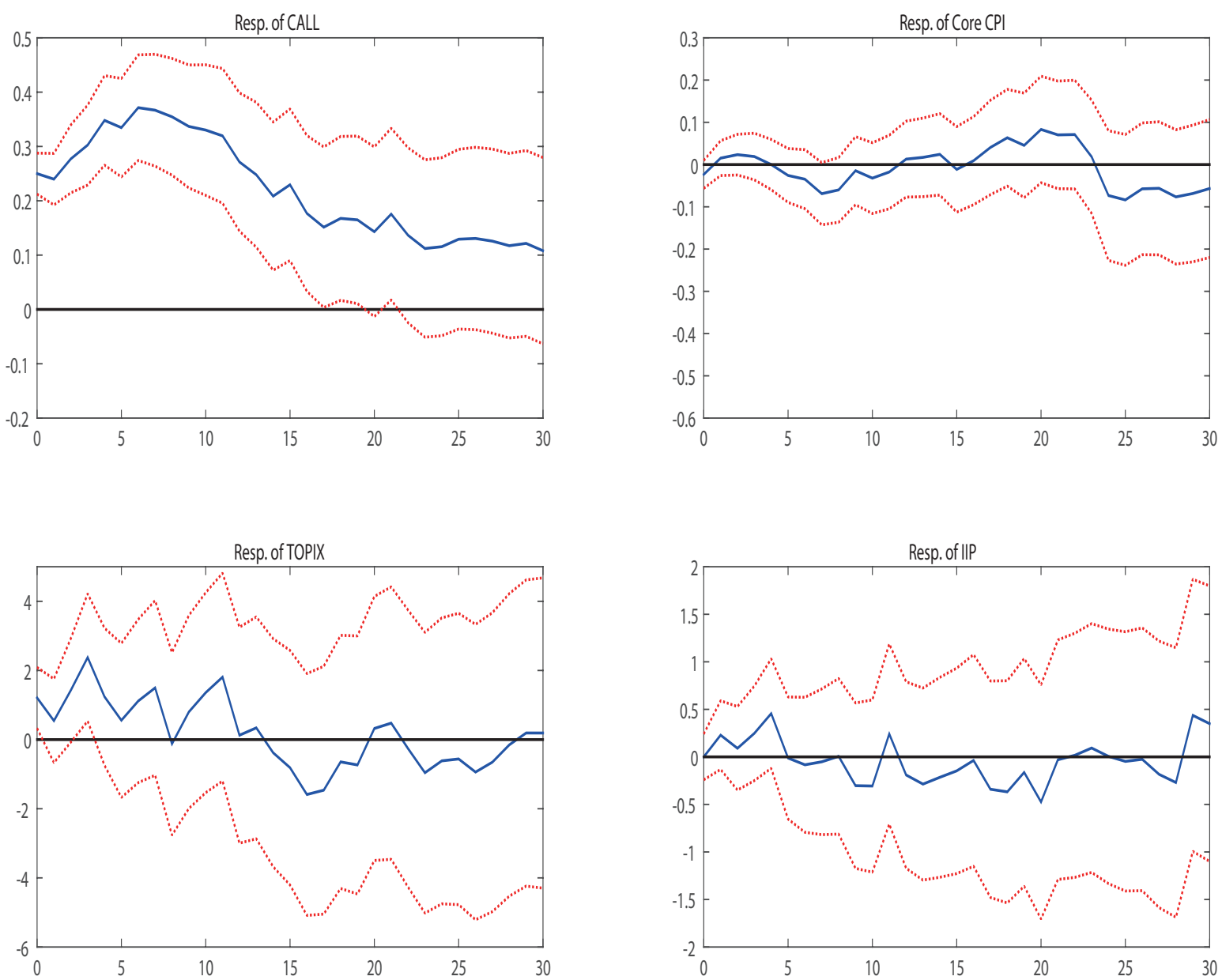

Figure 2: Impulse Responses to a Monetary Policy VAR Shock (4 variable VARs)

Note: The solid lines represent the point estimates of the impulse responses to a monetary policy VAR shock. The shock size is normalized to produce a 25-basis-point rise in the call rate on impact. The dotted lines represent standard error bands. The horizontal axis denotes the months from the shock (up to 30 months). 

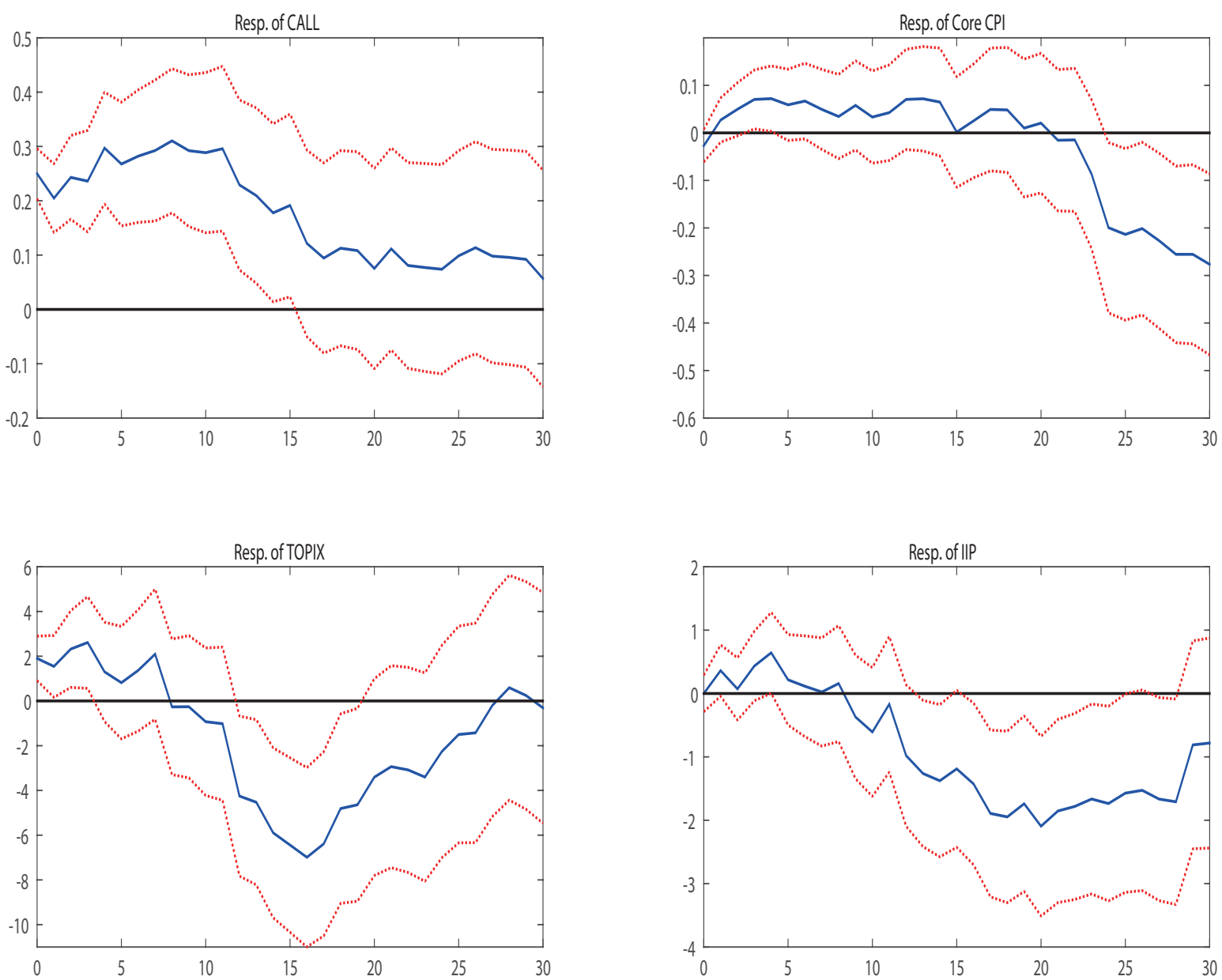

Figure 3: Impulse Responses to a Monetary Policy VAR Shock (5 variable VARs)

Note: The solid lines represent the point estimates of the impulse responses to a monetary policy VAR shock. The shock size is normalized to produce a 25-basis-point rise in the call rate on impact. The dotted lines represent standard error bands. The horizontal axis denotes the months from the shock (up to 30 months). 